Meta

Journal des traducteurs

Translators' Journal

\title{
Dictionnaire universel des traducteurs
}

\section{Henri Van Hoof}

Volume 33, numéro 3, septembre 1988

URI : https://id.erudit.org/iderudit/003089ar

DOI : https://doi.org/10.7202/003089ar

Aller au sommaire du numéro

Éditeur(s)

Les Presses de l'Université de Montréal

ISSN

0026-0452 (imprimé)

1492-1421 (numérique)

Découvrir la revue

Citer cette note

Van Hoof, H. (1988). Dictionnaire universel des traducteurs. Meta, 33(3),

462-464. https://doi.org/10.7202/003089ar d'utilisation que vous pouvez consulter en ligne.

https://apropos.erudit.org/fr/usagers/politique-dutilisation/ 
AKHALCHENICHVILI I. (XIX-XXe s.)

1. Traducteur géorgien.

2. A traduit de l'allemand : Die Leiden des jungen Werther (1909) de Goethe (1749-1832) ; du russe : des cuvres de Dostoïevski (1821-1881), Tchekhov (1860-1904), etc.

AKHMATOVA Anna (1889-1966)

1. Poétesse russe, née à Kiev, morte à Moscou. De son vrai nom Anna Gorenko. Épouse du poète Nikolaï Goumiliov.

2. Auteur de traductions de poésie de nombreuses langues, y compris le coréen et l'égyptien.

AKOP Grigor (XIX-XXe s.)

1. Traducteur arménien.

2. A traduit de l'allemand, librement, le Faust $I$ (1929) de Goethe (1749-1832), ainsi que les drames Goetz von Berlichingen, Clavigo, Stella et Die Geschwister, du même auteur, réunis en volume en 1930

AKSAKOV Sergeï (1791-1859)

1. Littérateur et critique dramatique russe, né à Ufa, mort à Moscou.

2. A traduit du français la tragédie Philactète (1816) de Jean-François de La Harpe (1739-1803), par laquelle il débuta dans les lettres.

ALAIGRE Antoine (XVIe s.)

1. Traducteur français.

2. A traduit de l'espagnol le Mespris de la court (1542) du franciscain Antonio de Guevara $(1480-1545)$

ALAMANNI Luigi (1495-1556)

1. Écrivain italien, né à Florence, mort à Amboise (France). Surintendant de la maison royale $\mathrm{de} \mathrm{Ca}$ therine de Médicis.

2. A traduit librement du latin les Géorgiques de Virgile (70-19 av. J.-C.) sous le titre la Culture des champs.

AL-ASAD ABU I-FARAJ HIBAT ALLAH (XIII's.)

1. Philologue et exégète copte de langue arabe. Auteur d'une grammaire copte en arabe.

2. A donné des Évangiles une version résumée en arabe.

\section{DICTIONNAIRE UNIVERSEL DES TRADUCTEURS}

(Cf. $M E T A, 32: 4$, pp. 499-502.)

AIKIN John (1747-1822)

1. Médecin et publiciste anglais, né à Kibworth Harcourt, mort à Stoke Newington. Études à Édimbourg, Londres et Leiden (Pays-Bas).

2. Eut également une activité de traducteur.
ALBERDINGK-THYM Jozef (1820-1889)

1. Écrivain romantique néerlandais, né et mort à Amsterdam.

2. A traduit du français la Fille de Roland, drame en vers du poète Henri Bornier (1825-1901).

\section{ALBERGATI CAPACELLI Francesco}

(1728-1804)

1. Dramaturge italien, né à Bologne, mort à Zola.

2. Traducteur de Voltaire (1694-1778), avec lequel il entretint une correspondance. 
ALBÉRIC de Besançon (XI" s.)

1. Moine français.

2. A traduit en octosyllabes romans le Roman d'Alexandre $( \pm 1100)$, d'après une version latine résumée de l'époque carolingienne.

ALBERT Henri (XIX-XX' s.)

1. Traducteur français.

2. Spécialiste de l'œuvre du philosophe allemand Friedrich Nietzsche (1844-1900), dont il a traduit la Volonté de puissance, Ainsi parla Zarathoustra (1898), Pages choisies (1899), la Généalogie de la morale (1900), Aurores, Réflexions sur les préjugés moraux (1901) et le Voyageur et son ombre (1902).

ALBERTINUS Aegidius (1560-1620)

1. Jésuite allemand, né à Deventer (Pays-Bas), mort à Munich. Bibliothécaire, puis conseiller à la cour de Maximilien Ier de Bavière.

2. Adaptateur de nombreux (plus de 1600 !) ouvrages français, italiens et espagnols de morale et d'éducation. Son adaptation de Guzman de Alfarache, de l'écrivain espagnol Mateo Aleman (1547-1614), sous le titre Der Landstörtzer Gusman von Alfarache oder Picaro genannt (1615) a préparé la voie au roman picaresque en Allemagne.

\section{ALBERTUS MAGNUS (1193-1280)}

1. Dominicain allemand, né à Lauingen, mort à Cologne.

L'un des plus illustres philosophes et savants du Moyen Âge. Enseigna la théologie et la philosophie en Allemagne et en France ; maitre de Thomas d'Aquin.

2. Dépouilla les travaux des Arabes et des rabbins qui avaient apporté en Occident des traductions de l'cuvre d'Aristote. Traduisit en latin les cuvres d'Aristote et d'Avicenne.

ALBINUS Johann (1624-1679)

1. Théologien et prédicateur allemand, né à Untermessa, mort à Naumburg.

2. A traduit Pia desideria de Hugon sous le titre Himmelfiammende Seeleniust (1675).

ALCALA GALIANO Antonio (1789-1865)

1. Écrivain espagnol, né à Cadix. Fin lettré. Réfugié en Grande-Bretagne à l'arrivée des Français.

2. A traduit de l'anglais les poésies de Byron (1788-1824)

ALCIONUS Pietro (1486-1527)

1. Philologue italien, né à Venise, mort à Rome. Titulaire de la chaire de grec à l'université de Florence.

2. A traduit du grec des cuvres des rhéteurs athéniens Isocrate (436-338 av. J.-C.) et Démosthène (384-322 av. J.-C.) et du philosophe Aristote (384-322 av, J.-C.)
ALCIPE (1750-1839)

1. Poétesse portugaise, née et morte à Lisbonne. De son vrai nom Léonor de Almeida.

2. A traduit de l'anglais : des poèmes d'Alexander Pope (1688-1744), James Thomson (1700-1748) et Edward Young (1683-1765); de l'allemand : des cuvres de Goethe (1749-1832).

\section{ALDHELM (639-709)}

1. Érudit anglais, né dans le Wessex, mort à Doulting. Évêque de Sherborne. Latiniste distingué.

2. Auteur de la première version anglo-saxonne des Psalms 1-50.

\section{ALDINGTON Richard (1892-1962)}

1. Poète et romancier anglais, né à Portsmouth, mort aux États-Unis où il émigra pendant la guerre 1940-1945.

2. Auteur de nombreuses traductions d'œuvres latines, grecques et italiennes.

ALDOBRANDINI, Tommaso (1540-1572)

1. Humaniste italien, né et mort à Rome. Secrétaire du pape Pie V.

2. Auteur d'une traduction inachevée des Vies des anciens philosophes de l'écrivain grec Diogène Laërce (II $\mathrm{s}$.), publiée en 1594.

\section{ALEXANDRE (XIXe s.)}

1. Traducteur français.

2. A traduit de l'allemand la Théorie de la preuve dans la procédure criminelle (1848) du juriste Karl Mittermaier (1787-1867) et l'Histoire romaine (8 vol., 1863-1872) de l'érudit Theodor Mommsen (1877-1903).

\section{ALEXANDRESCU Grigore (1810-1885)}

1. Écrivain et homme politique roumain, né à Tirgoviste, mort à Bucarest. Grand connaisseur des littératures classique et française.

2. Auteur de traductions d'œuvres latines et françaises.

\section{ALEXIS Willibald (1798-1871)}

1. Écrivain, journaliste et éditeur allemand, né à Breslau, mort à Armstadt. Créateur du romanfresque historique.

2. A traduit de l'anglais des romans de Walter Scott (1771-1832).

\section{ALFORD Henry (1810-1871)}

1. Théologien, érudit et poète anglais, né à Londres, mort à Canterbury. Auteur d'une monumentale édition du Nouveau Testament (4 vol.) en grec.

2. A traduit du grec l'Odyssey d'Homère (VIII' $\mathrm{s}$. av. J.-C.).

\section{ALFRED Le Grand (849-899)}

1. Premier souverain anglo-saxon, né à Wantage. Exerça une influence prépondérante sur l'instruction par la création de nombreuses écoles, en im- 
portant des maîtres étrangers et en traduisant luimême de nombreux ouvrages.

2. A traduit du latin Ecclesiastical History of England de Bède le Vénérable (673-735), Universal History de Paul Orose (Iv-ve s.), Pastoral Care, un manuel religieux du pape Grégoire le Grand (540-604), les Soliloquia de saint Augustin (354-430), et surtout On the Consolation of Philosophy du philosophe romain Boèce (480-524), probablement la meilleure des traductions royales.

Dans l'ensemble, les traductions d'Alfred, qui selon ses propres paroles - suivent « tantôt la lettre, tantôt le sens", sont souvent inexactes parce qu'il s'écarte de l'original dans une intention pédagogique.

AL-HARIZI Jehuda ben Salomon ben ( ?-1235)

1. Rabbin espagnol, né à Jerez.

2. A traduit en hébreu les Makâmat (Conférences) de l'écrivain arabe El-Hariri (1054-1122).

ALLAMA Abdullah Yusuf Ali (XIX' s.)

1. Ancien directeur du Collège Islamiya de Lahore.
2. Auteur d'une traduction anglaise du Coran, la seule qui a tenté de conserver le rythme et la poésie de l'original arabe.

ALLEN John (XIX'c s.)

1. Traducteur anglais.

2. A traduit du français Institutes of the Christian Religion (1873) du réformateur Jean Calvin (1509-1564).

ALLINSON F.G. (XIX-XXe s.)

1. Traducteur anglais.

2. A traduit le Fabularum reliquiae (1921) du dramaturge grec Ménandre (342-291 av. J.-C.).

ALLISON R. (XIX-XXe s.)

1. Traducteur anglais.

2. Auteur d'une traduction en vers des Comédies (1914) du poète latin Plaute (254-184 av. J.-C.)

HENRI VAN HOOF Commission Histoire et Théorie de la Traduction de la FIT 